\title{
Characterization of fluoride releasing restorative dental materials
}

\author{
Sufyan GAROUSHI ${ }^{1}$, Pekka K. VALLITTU1,2 and Lippo LASSILA ${ }^{1}$ \\ ${ }^{1}$ Department of Biomaterials Science and Turku Clinical Biomaterials Center -TCBC Institute of Dentistry, University of Turku, Turku, Finland \\ ${ }^{2}$ City of Turku Welfare Division, Oral Health Care, Turku, Finland \\ Corresponding author, Sufyan GAROUSHI; E-mail: sufgar@utu.fi
}

\begin{abstract}
This study aimed to evaluate and compare certain mechanical properties, Vickers-hardness, water sorption, fluoride-release, shrinkage-stress and wear of five commercial fluoride-releasing restorative materials (Dyract, CompGlass, BEAUTIFIL II, ACTIVARestorative, and GC Fuji II LC), in relation to their microstructural characteristics. Mechanical properties were determined for each material following ISO standards. A wear test was conducted with 15,000 chewing cycles using a dual-axis chewing simulator. Daily fluoride-release was measured during the first 10 days by using a fluoride ion selective electrode. Scanning electron microscopy (SEM) was used to evaluate the microstructure of each material. Results were statistically analysed using ANOVA followed by post hoc Tukey's test. ACTIVA-Restorative exhibited the highest fracture toughness $\left(1.1 \mathrm{MPa} \mathrm{m}^{1 / 2}\right)$ among the materials tested. BEAUTIFIL II presented the highest flexural strength (145 MPa) which was not significantly different ( $p>0.05)$ from CompGlass and Dyract. Highest fluoride-release measurement was located for GC Fuji II LC among other tested materials.
\end{abstract}

Keywords: Fluoride release composite, Fracture toughness, Wear, Mechanical properties

\section{INTRODUCTION}

The use of fluoride releasing materials for restoring cavities and build-up cores has increased rapidly in recent years ${ }^{1}$. There are several fluoride containing hybrid restorative materials available in the market including resin modified glass ionomers, compomers, giomers and bioactive resin composites. These hybrid materials were introduced to overcome the problem associated with conventional glass ionomers and composite resins and maintain their clinical advantages ${ }^{1}$. These materials have different setting mechanisms between acid-base reaction and free radical polymerization. Resin modified glass ionomers are hybrid materials that retain a significant acidbase reaction as part of their overall curing process. In contrast, compomers are materials that may contain either or both of the essential components of glass ionomers but at levels insufficient to promote an acidbase curing reaction in the $\mathrm{dark}^{2}$. Compomers are anhydrous and the glass ionomer phase can be formed only upon water uptake into the resin matrix. On the other hand, giomers employ the use of prereacted glass ionomer (PRG) technology to form the glass ionomer phase $^{3)}$. Giomers incorporate fillers that are produced from the complete or partial reaction of ion-leachable glasses with polyalkenoic acids. Since PRG fillers are pre-reacted, acidic resin monomers are not necessary for in situ acid-base reactions ${ }^{3)}$.

Beside the ability to release fluoride and inhibit recurrent caries, fluoride releasing materials have the advantage of natural shade and they are less expensive compared with cast gold and ceramic restorations.

Color figures can be viewed in the online issue, which is available at J-STAGE.

Received May 16, 2017: Accepted Jul 12, 2017

doi:10.4012/dmj.2017-161 JOI JST.JSTAGE/dmj/2017-161
However, insufficient material properties and brittleness limited the clinical success of these materials in high stress bearing areas ${ }^{4,5}$. Fracture within the body (bulk) and margins of restorations have been cited as major problems regarding the failure of these materials ${ }^{4}$. The fracture related material properties, such as fracture resistance, deformation under occlusal load, and the marginal degradation of materials have usually been evaluated by the determination of the basic material parameters of fracture toughness and flexural strength ${ }^{6}$. Consequently, the property of fracture toughness and flexural strength become important criterions in a dental materials' longevity ${ }^{6,7)}$. With the passage of time, wear, fatigue, and internal stress-strain from thermal contraction and expansion may create plastic deformation and marginal leakage ${ }^{8,9)}$. The requirement to strengthen and improve fluoride releasing dental materials has lead to an ever increasing research effort into reinforcement techniques.

A new type of bioactive resin based composite (ACTIVA-Restorative, Pulpdent, Watertown, MA, USA) was launched globally in $2013^{10,11}$. This new product was considered equivalent to resin modified glass ionomers. However, even though it contains the glass particles and polyacid components of glass ionomer, which undergo the acid-base setting reaction, they are also formulated with a bioactive ionic resin matrix, having both light polymerization ability and chemical cure. Thus, there are three hardening mechanisms involved with the ACTIVA product ${ }^{10,11}$. According to the manufacturer, this restorative material is the first bioactive dental material with an ionic resin matrix and bioactive fillers that mimic the physical and chemical properties of natural teeth. They also claimed that ACTIVA has more fluoride ions release than glass ionomers. In view of the 
development of newer materials in the market, clinician often has uncertainties regarding the choice of best materials to achieve optimum results. A comparative evaluation of available fluoride releasing restorative materials would help the clinician to select better products. Thus, the aim of this study was to evaluate and compare certain mechanical properties, Vickers hardness, water sorption, fluoride release, shrinkage stress and wear of five commercial fluoride releasing restorative materials (Dyract, CompGlass, BEAUTIFIL II, ACTIVA-Restorative, and GC Fuji II LC), in relation to their microstructural characteristics.

\section{MATERIALS AND METHODS}

Five commercial fluoride release restorative materials representing the continuum were selected. They included a resin modified glass ionomer, a high and low viscous compomers, a giomer, and bioactive resin composite. The materials evaluated and their manufacturers are shown in Table 1. All materials were of the A3 shade and were manipulated according to the manufacturer's recommended directions.

\section{Mechanical tests}

Three-point bending test specimens $\left(2 \times 2 \times 25 \mathrm{~mm}^{3}\right)$ were made from each tested composite. Bar-shaped specimens were made in a half-split stainless steel mold between transparent Mylar sheets. Polymerization of the materials was done using a hand light-curing unit (Elipar S10, 3M ESPE, St. Paul, MN, USA) for $20 \mathrm{~s}$ in five separate overlapping portions from both sides of the metal mold. The wavelength of the light was between 430 and $480 \mathrm{~nm}$ and light intensity was $1,600 \mathrm{~mW} / \mathrm{cm}^{2}$. The specimens from each material $(n=8)$ were either stored dry (for one day) or stored in water (for 37 days) at $37^{\circ} \mathrm{C}$ degree before testing. Three-point bending test was conducted according to the ISO 4049 (test span: $20 \mathrm{~mm}$, cross-head speed: $1 \mathrm{~mm} / \mathrm{min}$, indenter: $2 \mathrm{~mm}$ diameter). All specimens were loaded in material testing machine (model LRX, Lloyd Instrument, Fareham, England) and the load-deflection curves were recorded with PCcomputer software (Nexygen 4.0, Lloyd Instruments).

Flexural strength (of) was calculated from the following formula (ISO 1992):

$$
\text { of }=3 \mathrm{FmI} / 2 \mathrm{bh}^{2}
$$

Where $\mathrm{F}_{\mathrm{m}}$ is the applied load $(\mathrm{N})$ at the highest point of a load-deflection curve, $\mathrm{I}$ is the span length $(20 \mathrm{~mm}), \mathrm{b}$ is the width of test specimens and $h$ is the thickness of test specimens.

Single-edge-notched-beam specimens $(2.5 \times 5 \times 25$ $\mathrm{mm}^{3}$ ) according to adapted ISO 20795-2 standard method (ASTM 2005) were prepared to determine the fracture toughness. Custom-made stainless steel split mold was used, which enabled specimen's removal without force. Accurately designed slot was fabricated centrally in the mold extending until its mid-height, which enabled central location of the notch and optimization of the crack length (x) to be 0.5 . The restorative material was inserted into the mold placed over a Mylar-strip-covered glass slide in one increment. Before polymerization a sharp and centrally located crack was produced by inserting a straight edged steel blade into the prefabricated slot. Polymerization of the composite was carried out for $20 \mathrm{~s}$ in five separate overlapping portions. The upper side of the mold was covered with Mylar strip and glass slide from both sides of the blade, before being exposed to the polymerization light. Upon the removal from the mold,

Table 1 The fluoride release materials investigated and their composition.

\begin{tabular}{|c|c|c|c|}
\hline Brand & Manufacturer & Type & Composition \\
\hline $\begin{array}{l}\text { Dyract } \\
\text { (shade A3) }\end{array}$ & $\begin{array}{l}\text { Dentsply, } \\
\text { Konstanz, } \\
\text { Germany }\end{array}$ & Compomer & $\begin{array}{l}\text { UDMA, TCB resin, TEGDMA, } \\
\text { trimethacrylate resin. } 73 \mathrm{wt} \% \text { Strontium- } \\
\text { alumino-sodium-fluoro-phosphor-silicate }\end{array}$ \\
\hline $\begin{array}{l}\text { CompGlass } \\
\text { (shade A3) }\end{array}$ & $\begin{array}{l}\text { Ivoclar Vivadent, } \\
\text { Schaan, } \\
\text { Liechtenstein }\end{array}$ & Compomer & $\begin{array}{l}\text { Dimethacrylates and ytterbium trifluoride, } \\
77.3 \mathrm{wt} \% \text { Barium-alumino-fluorosilicate glass }\end{array}$ \\
\hline $\begin{array}{l}\text { ACTIVA-Restorative } \\
\text { (shade A3) }\end{array}$ & $\begin{array}{l}\text { Pulpdent, } \\
\text { Watertown, } \\
\text { MA, USA }\end{array}$ & $\begin{array}{l}\text { Bioactive } \\
\text { composite }\end{array}$ & $\begin{array}{l}\text { Blend of diurethane and other methacrylates } \\
\text { with modified polyacrylic acid. } \\
55.4 \text { wt\% Bioactive glass and sodium fluoride }\end{array}$ \\
\hline $\begin{array}{l}\text { BEAUTIFIL-II } \\
\text { (shade A3) }\end{array}$ & $\begin{array}{l}\text { Shofu, } \\
\text { Kyoto, Japan }\end{array}$ & Giomer & $\begin{array}{l}\text { Bis-GMA, UDMA, Bis-MPEPP, TEGDMA. } \\
83.3 \text { wt\% Fluoro-silicate glass }\end{array}$ \\
\hline $\begin{array}{l}\text { GC Fuji II LC } \\
\text { (shade A3) }\end{array}$ & $\begin{array}{l}\text { GC, } \\
\text { Tokyo, Japan }\end{array}$ & RMGIC & $\begin{array}{l}\text { 2-hydroxyethyl methacrylate, Polyacrylic acid } \\
\text { and water. } 58 \text { wt\% Fluoro-aluminumsilicate }\end{array}$ \\
\hline
\end{tabular}

RMGIC: resin modified glass-ionomer cement; Bis-GMA: bisphenol-A-diglycidyl-methacrylate; TEGDMA: triethyleneglycol dimethacrylate; UDMA: urethane dimethacrylate; Bis-MPEPP: Bisphenol A polyethoxy Methacrylate; TCB: Carboxylic acid modified di-methacrylate; wt\%: weight percentage. 
each specimen was polymerized also on the opposite side. The specimens from each group $(n=8)$ were stored dry at $37^{\circ} \mathrm{C}$ for $24 \mathrm{~h}$ before testing. The specimens were tested in three-point bending mode, in a universal material testing machine at a crosshead speed of $1.0 \mathrm{~mm} / \mathrm{min}$.

The fracture toughness was calculated using the Equation:

$$
\mathrm{K}_{\max }=\left[\mathrm{P} \mathrm{L} / \mathrm{B} \mathrm{W}^{3 / 2}\right] \mathrm{f}(\mathrm{x}),
$$

where: $f(x)=3 / 2 \times 1 / 2[1.99-x(1-x)(2.15-3.93 x+2.7 \times 2)] / 2$ $(1+2 x)(1-x) 3 / 2$ and $0<x<1$ with $x=a / W$. Here $P$ is the maximum load in kilonewtons $(\mathrm{kN}), \mathrm{L}$ is the span length $(20 \mathrm{~cm}), \mathrm{B}$ is the specimen thickness in centimeters $(\mathrm{cm})$, $\mathrm{W}$ is the specimen width (depth) in $\mathrm{cm}, \mathrm{x}$ is a geometrical function dependent on $\mathrm{a} / \mathrm{W}$ and $\mathrm{a}$ is the crack length in $\mathrm{cm}$.

\section{Wear test}

Two specimens of each commercial materials were prepared in acrylic resin block for localized wear testing. Longitudinal cavities $(20 \mathrm{~mm}$ length $\times 10 \mathrm{~mm}$ width $\times 2$ $\mathrm{mm}$ depth) were prepared in and then materials were placed in one increment into the prepared cavities and covered with a Mylar strips and glass slides before light irradiated for $40 \mathrm{~s}$ in five separate overlapping portions. The surfaces were then polished flat using a sequence of \#1200- to \#4000-grit silicon carbide papers. After one day of storage $\left(37^{\circ} \mathrm{C}\right), 2$-body wear test was conducted using the chewing simulator CS-4.2 (SD Mechatronik, Feldkirchen-Westerham, Germany) which has two chambers simulating the vertical and horizontal movements simultaneously with water. Each of the chambers consists of an upper sample holder that can fasten the loading tip with a screw and a lower plastic sample holder in which the specimen can be embedded. The specimens were embedded in acrylic resin in the lower sample holder, for use as antagonistic wear materials. The manufacturer's standard loading balls (Ø $6 \mathrm{~mm}$ ) were embedded in acrylic resins in the upper sample holders, and were then fixed with a fastening screw. A weight of $2 \mathrm{~kg}$, which is comparable to $20 \mathrm{~N}$ of chewing force and 15,000 loading cycles with frequency of $1.5 \mathrm{~Hz}$ were used.

The wear patterns $(n=4)$ on the surface of each specimen were profiled with 3D optical microscope (Bruker Nano, Berlin, Germany) using Vision64 software. The maximum wear depth values $(\mu \mathrm{m})$, representing the average of lowest or deepest points of all profile scans were calculated from different points (Fig. 1).

\section{Shrinkage-stress measurement}

Glass fiber reinforced composite rods with $4 \mathrm{~mm}$ diameter and $4 \mathrm{~cm}$ length had one of their flat surfaces ground with 180 grit silicon carbide sand paper. Two FRC rods were attached tightly to a universal testing machine (model LRX, Lloyd Instruments) and tested material was applied between the FRC rods surfaces. The height of the specimen was set at $1.5 \mathrm{~mm}$. Two light units (Elipar S10, 3M ESPE) were used simultaneously for $20 \mathrm{~s}$ with the tips in close contact with material specimen from both sides. Contraction forces were monitored for 5 min. Shrinkage stress was calculated by dividing the shrinkage force by the cross-section area of the FRC rod. The maximum shrinkage stress value was taken from the plateau at the end of shrinkage stress/time curve. Five specimens were tested for each fluoride releasing material.

\section{Vickers hardness}

Three specimens form each fluoride releasing material (2 mm-thick rings with a diameter of $6.5 \mathrm{~mm}$ ) were prepared. After polymerization, specimens were polished (grit up to $4000 \mathrm{FEPA}$ ) at $300 \mathrm{rpm}$ under water cool using
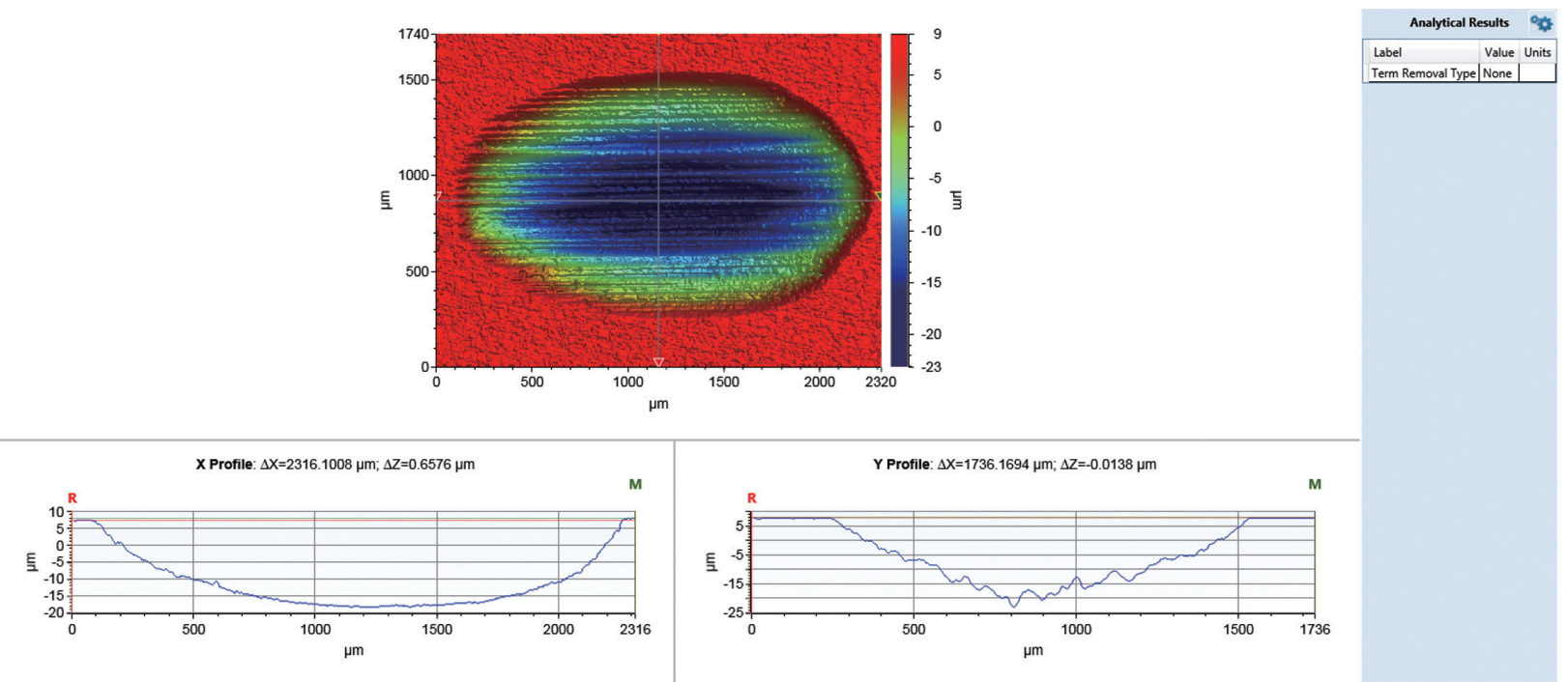

Fig. 1 Typical 3D surface profile of the wear pattern where wear depth was measured. 
an automatic grinding machine (Steruers Rotopol-11, Copenhagen, Denmark). Specimens were dry stored for $24 \mathrm{~h}$ at $37^{\circ} \mathrm{C}$ before testing. Hardness measurements (10 points for each specimen) were carried out with universal Vickers device (Duramin, Struers). A load of $1.96 \mathrm{~N}$ was applied during $10 \mathrm{~s}$ on their surface. The length of the diagonal of each indentation was measured directly using a graduated eye-lens. The Vickers hardness number (VHN) is obtained using the following equation:

$$
\mathrm{H}=\frac{1854.4 \times \mathrm{P}}{\mathrm{d}^{2}}
$$

where $\mathrm{H}$ is Vickers hardness in $\mathrm{kg} / \mathrm{mm}^{2}$, $\mathrm{P}$ is the load in grams and $d$ is the length of the diagonals in $\mu \mathrm{m}$.

\section{Water uptake}

Water sorption was measured from eight specimens (test specimens for the three-point bending test) which were stored in $120 \mathrm{~mL}$ water for 37 days at $37^{\circ} \mathrm{C}$. The dry weight (md) of the specimens was measured with a balance (Mettler A30, Mettler Instrument, Highstone, NJ, USA), with an accuracy of $0.1 \mathrm{mg}$. During water immersion, specimen weight (mw) was measured at $1,2,3,10,14,28,31$ and 37 days. Water uptake was calculated as follows:

Water uptake $\%=(\mathrm{mw}-\mathrm{md}) / \mathrm{md} \times 100 \%$

\section{Fluoride release measurement}

Five disc-shaped specimens for each fluoride releasing material were prepared in a metal mold $(8 \mathrm{~mm}$ in diameter and $2 \mathrm{~mm}$ in thickness). The material was packed into the mold and covered on both sides with Mylar strips and microscopic glass slides to extrude the excess material. Polymerization was performed according to manufacturer recommendation. All specimens were then polished to remove the resin rich surface layer and each specimen was immersed in a plastic container containing $5 \mathrm{~mL}$ of deionized water at $37^{\circ} \mathrm{C}$. After $24 \mathrm{~h}$, the containers were thoroughly shaken and the water removed and analyzed. The specimens were then reimmersed in $5 \mathrm{~mL}$ of fresh deionized water for further equilibration. Measurements of fluoride released was studied every $24 \mathrm{~h}$ for the 10 days. Each $5 \mathrm{~mL}$ storage water was mixed with $0.5 \mathrm{~mL}$ of ionic strength adjustable buffer (TISAB III) solution and analyzed for fluoride ions with the use of an ion-specific electrode (Orion Electrode, Orion Research, Boston, MA, USA) connected to an ion analyzer supplied with the measuring unit. The solution was gently stirred during the analysis in a non heated magnetic stirrer. The system was calibrated prior to each evaluation with fluoride standards ranging from 0.2 to $100 \mathrm{ppm}$. Mean and standard deviation values of fluoride release ions were calculated in ppm for each day.

\section{Microscopic analysis}

Scanning electron microscopy (SEM, JSM 5500, JEOL, Tokyo, Japan) provided the characterization of the microstructure of the investigated materials. The specimens $(n=3)$ from each group were gold sputter coated before the SEM examination.

\section{Statistical analysis}

The data were statistically analyzed with SPSS version 23 (SPSS, IBM, Armonk, NY, USA) using analysis of variance (ANOVA) at the $p<0.05$ significance level followed by a Tukey HSD post hoc test to determine the differences between the groups.

\section{RESULTS}

The mean values of flexural strength (FS), fracture toughness (FT), shrinkage stress (SS), wear and Vickers hardness of tested fluoride release materials with standard deviations (SD) are summarized in Table 2.

BEAUTIFIL II presented the highest flexural strength $(145,119 \mathrm{MPa})$ in both dry and wet conditions among all tested materials. However, the difference was not significant $(p>0.05)$ from CompGlass and Dyract at dry condition. On the other hand, resin modified glass ionomer (GC Fuji II LC) had the lowest flexural strength values $(p<0.05)$ in both dry and wet conditions $(55,25 \mathrm{MPa})$. ACTIVA-Restorative exhibited the highest fracture toughness $\left(1.1 \mathrm{MPa} \mathrm{m}^{1 / 2}\right)$ among the materials

Table 2 Tested properties mean values $( \pm \mathrm{SD})$ of investigated fluoride release materials

\begin{tabular}{|c|c|c|c|c|c|c|}
\hline Material & $\begin{array}{l}\text { FS-dry } \\
\text { (MPa) }\end{array}$ & $\begin{array}{l}\text { FS-wet } \\
(\mathrm{MPa})\end{array}$ & $\begin{array}{c}\mathrm{FT} \\
\left(\mathrm{MPa} \mathrm{m}^{1 / 2}\right)\end{array}$ & $\begin{array}{c}\mathrm{SS} \\
(\mathrm{MPa})\end{array}$ & $\begin{array}{l}\text { Wear } \\
(\mu \mathrm{m})\end{array}$ & $\begin{array}{c}\text { Vickers } \\
\text { hardness (VH) }\end{array}$ \\
\hline Dyract & $135^{\mathrm{c}} \pm 16$ & $77^{\mathrm{b}} \pm 12$ & $0.7^{\mathrm{a}} \pm 0.1$ & $3.4^{\mathrm{a}} \pm 0.3$ & $36^{\mathrm{b}} \pm 3$ & $71^{\mathrm{d} \pm 2}$ \\
\hline CompGlass & $132^{\mathrm{c}} \pm 20$ & $76^{\mathrm{b}} \pm 9$ & $0.8^{\mathrm{ab}} \pm 0.1$ & $3.5^{\mathrm{a}} \pm 0.4$ & $47^{\mathrm{c}} \pm 6$ & $48^{\mathrm{b}} \pm 2$ \\
\hline ACTIVA-Restorative & $100^{\mathrm{b}} \pm 12$ & $70^{\mathrm{b}} \pm 8$ & $1.1^{\mathrm{cd}} \pm 0.1$ & $3.8^{\mathrm{a}} \pm 0.2$ & $23^{\mathrm{a}} \pm 3$ & $38^{\mathrm{a}} \pm 3$ \\
\hline BEAUTIFIL-II & $145^{\mathrm{cd}} \pm 18$ & $119^{c} \pm 8$ & $1.0^{\mathrm{c}} \pm 0.1$ & $3.4^{\mathrm{a}} \pm 0.4$ & $48^{\mathrm{c}} \pm 6$ & $54^{\mathrm{c}} \pm 2$ \\
\hline GC Fuji II LC & $55^{\mathrm{a}} \pm 9$ & $25^{\mathrm{a}} \pm 7$ & $0.8^{\mathrm{ab}} \pm 0.1$ & $3.7^{\mathrm{a}} \pm 0.3$ & $41^{\mathrm{bc}} \pm 5$ & $68^{\mathrm{d}} \pm 7$ \\
\hline
\end{tabular}

FS: flexural strength; FT: fracture toughness; SS: shrinkage stress. Same superscript letter above the values indicates groups that were not statistically different $(p>0.05)$. 


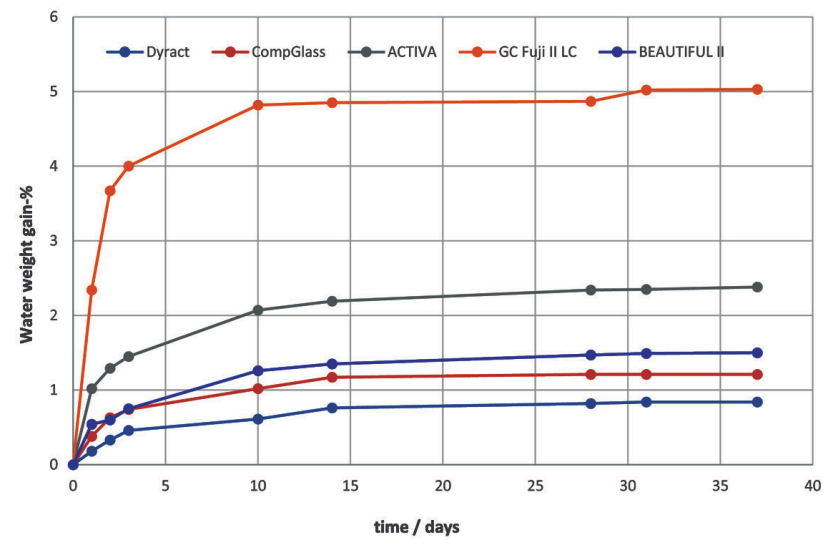

Fig. 2 Water sorption (\%wt gain) of investigated materials during 37 days of storage in water at $37^{\circ} \mathrm{C}$.

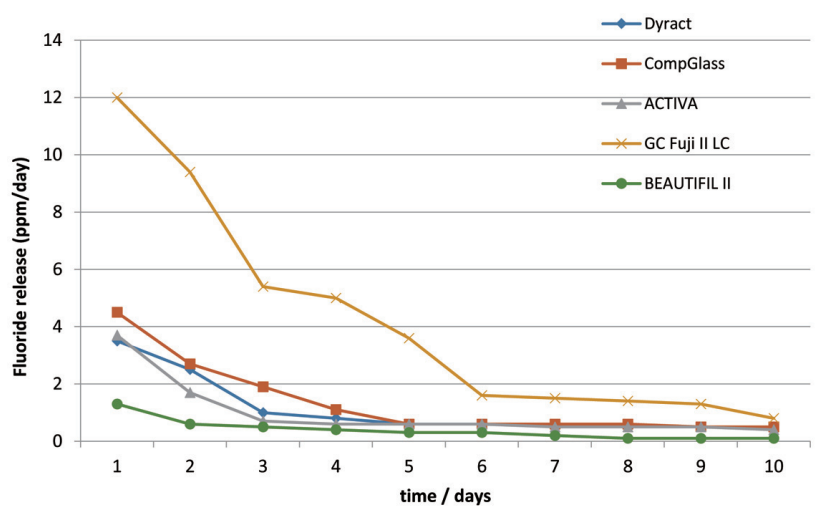

Fig. 3 Fluoride release pattern of investigated materials during the first 10 days.
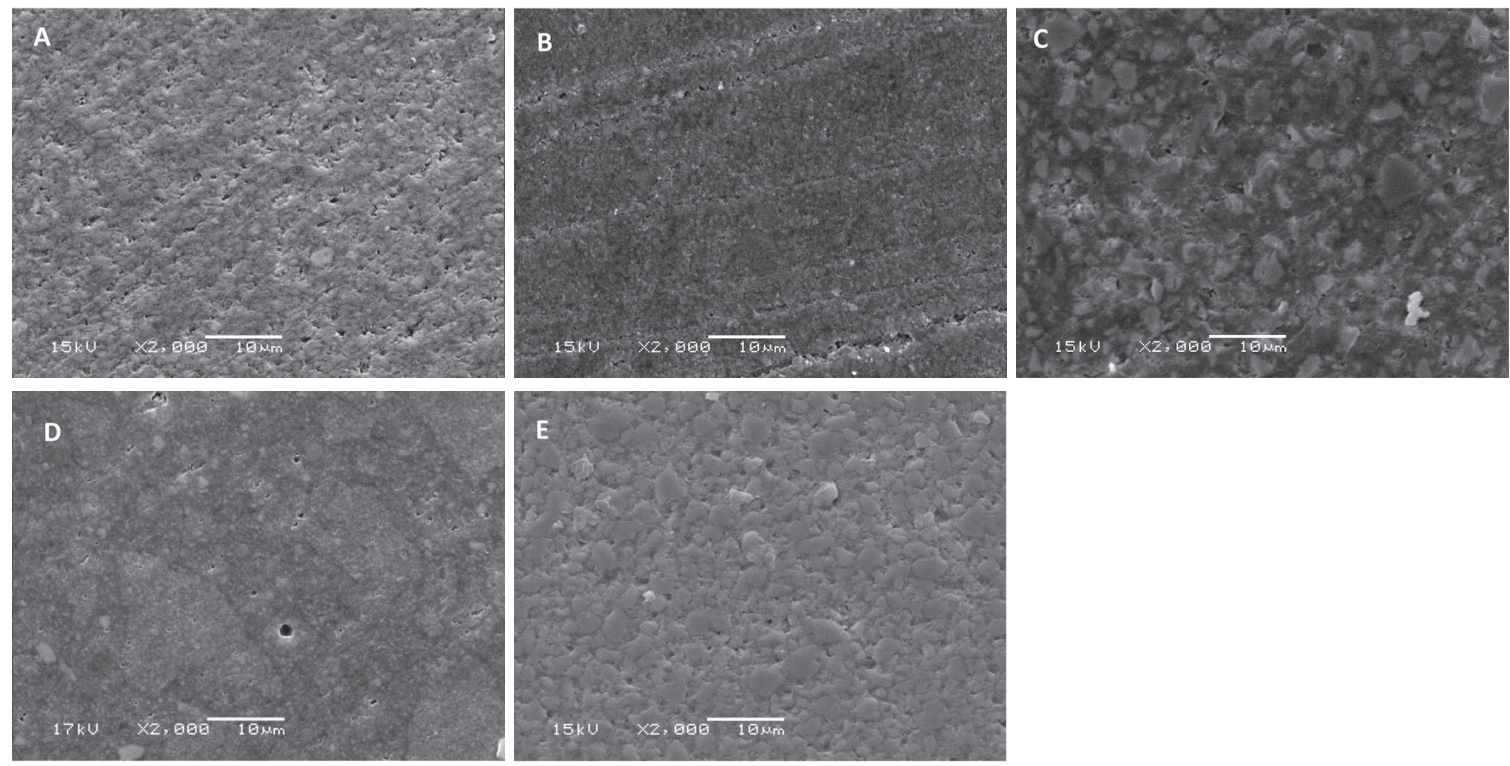

Fig. 4 SEM photomicrographs of polished surface of investigated bioactive restorative materials.

(A) Dyract; (B) CompGlass; (C) ACTIVA; (D) BEAUTIFIL-II; (E) GC Fuji II LC.

tested, although the difference was not statistically significant from BEAUTIFIL II $(p>0.05)$. No differences found in shrinkage stress between tested materials. The lowest wear depth and Vickers hardness value were found for ACTIVA-Restorative (23 $\mu \mathrm{m}, 38 \mathrm{VH})$.

Water sorption after 37 days of GC Fuji II LC was 5 wt\%, which was the highest among all tested materials (Fig. 2). Then again, the highest daily fluoride release measurement was located for GC Fuji II LC among other materials (Fig. 3). SEM analysis showed typical microstructure of each tested material with different particulate fillers size and shape in polymer matrix (Fig. 4). This suggested an explanation for different behaviors between tested materials.

\section{DISCUSSION}

Five different commercially available fluoride releasing restorative materials were evaluated in this study. Criteria for selecting the material was their fluoride releasing property and indication in restorative dentistry. Tested materials were known to have different clinical indications and comparison of properties in relation to the materials clinical use may not be justified. A large variation in the loading and constitution of filler particles can be seen (Table 1) in the different commercial materials tested. Depending on the test, the new bioactive resin based composite (ACTIVARestorative) had different properties compared to the resin modified glass ionomer, compomers, and giomer. 
Because these fluoride releasing restorative materials encompass different chemical characteristics and polymerization process, a diverse range in material performance were observed in our study.

The fracture toughness of a material is a measure of how well that material hinders the progress of a crack or flaw under load. Fracture toughness correlates to the fracture energy that is consumed in plastic deformation and proposes to approximate the crack growth rate ${ }^{12,13)}$. During mastication, the ability of a restorative material to withstand fracture critically depends on the growth of micro- and macro-voids, mechanisms of propagation of micro-cracks, and the geometry of the material ${ }^{12,13)}$. Recent systemic review by Heintze et al. showed that fracture toughness being mostly correlated with clinical fracture of composite resins and no correlations were observed between clinical outcomes and flexural modulus or flexural strength of these materials ${ }^{6}$. Microscopically, the presence of the filler particles distributes the propagating nominal force into many components, causes the crack front to curve or dissipate between particles, and becomes energetically unfavorable for a crack to grow. In theory, if filler contents were increased with decreasing particle size and inter-particle spacing, this would increase the fatigue limit due to increased obstacles for crack growth and limit the stresses at the crack tip around a plastic zone to finite values below the maximum allowable stresses ${ }^{13,14}$. However, studies with composites have demonstrated that critical strain energy release rate can be increased with incorporation of a specific filler-volume fraction, but beyond the critical filler content, the energy release rate reduces ${ }^{14,15)}$. Thus, there may exist a most favorable particle size and fillervolume fraction that could produce an optimal critical stress-intensity factor. Therefore, this would help to explain why there was no significant difference for fracture toughness measurements among compomer materials (Dyract, CompGlass), and the low filled resin modified glass ionomer (GC Fuji II LC). Each of these materials may have an optimal proportion between particle size and filler-volume fraction. On the contrary, the new bioactive composite (ACTIVA-Restorative) and the highly filled giomer (BEAUTIFIL-II) were measured to have the highest fracture toughness values (Table 2). This finding are in agreement with previous studies, which reported higher fracture toughness and flexural fatigue values of BEAUTIFIL-II and ACTIVARestorative in comparison with some commercial fluoride releasing materials ${ }^{13,16)}$. According to manufacturer report, ACTIVA-Restorative contains a resilient resin matrix with energy-absorbing elastomeric components (a blend of diurethane and methacrylates with modified polyacrylic acid), which could be an explanation for the high fracture toughness value.

In this study, a three-point bending test was used to measure the flexural strength of the materials. This commonly used test is designed as the primary strength test for resin containing dental restorative materials under the international testing standard (ISO 4049) ${ }^{17}$. Flexural strength of a material represents the maximum stress it withstands before failure when subjected to bending loads. For load-bearing restorations in the posterior region (Class I/Class II) the test demands a mean minimal flexural strength value of $80 \mathrm{MPa}$ and no other mechanical test is included in any ISO standard related to dental polymer materials ${ }^{6)}$.

From our experiments, the materials presented the following decreasing order of flexural strength (Table 2): Giomer $>$ Compomers $>$ Bioactive composite $>$ Resin modified glass ionomer. This in accordance with previous studies which showed a positive correlation between filler-volume fraction and flexural strength ${ }^{15,18)}$.

Resin containing restorative materials are prone to hydrolytic degradation as an effect of water on the silane interface as well as by softening and weakening of the matrix itself due to an absorption of water by resin components ${ }^{19)}$. Previous researchers have also suggested that leaching of ions from filler particles of regular fluoride releasing materials may cause a filler-matrix debonding as a result of a weakened filler surface $\mathrm{e}^{20,21)}$. Soderholm et al. attributed the leaching of ions to the formation of microcracks along matrix-filler interfaces, and related the highest crack density with the highest leaching per unit area of filler ${ }^{21}$. The mechanism of microcrack formation in the matrix is further described as a result of osmotic pressure building up in pre-existing cavities inside the material owing to water accumulation and filler leakage ${ }^{20)}$. This is supposed to be reflected in a high degradation of the mechanical properties in the fluoride releasing restorative materials. The present data confirm this assumption, since the flexural strength of the analyzed materials are decreased dramatically after 37 days of immersion (Table 2). Among all tested materials, BEAUTIFIL-II displayed the most stable material. This fact might be attributed to the particular structure of the S-PRG fillers. In contrast to resin modified glass ionomer and compomer materials, the acid-base reaction in giomer occurred in S-PRG fillers during manufacturing, thus resulting in a surface modified layer which is described as consequently protecting the glass core from the damaging effects of moisture ${ }^{20,22)}$. Moreover, the stable mechanical properties of the analyzed giomer restorative might also be attributed, at least partially, to the incorporation of different types of filler in the material amounting in total to $83.3 \mathrm{wt} \%$, including, besides S-PRG fillers, also large pre-polymerized fillers (Fig. 4D).

One important factor that should be considered in the selection of restorative materials in clinical practice is their wear resistance. Wear rate is defined as the loss of restorative material and/or its antagonist, which may led to loss of anatomical form and function ${ }^{23)}$. The chewing simulation assay as used in this study included the vertical application of masticatory force to simulate direct contact between the test specimen and its antagonist, as well as additional lateral movement of the specimen carrier. Thus, both abrasive and fatigue wear were simulated in one mastication simulation assay ${ }^{23)}$. It has been reported that abrasive wear is proportional to the hardness of the materials in contact, 
the geometry of the abrasive particles, the applied load, and the sliding distance ${ }^{24)}$. For composite materials, the filler particles play a particular important role for both hardness and wear resistance: McCabe and Wassell found that for composite materials with silanated fillers, hardness increased with filler content ${ }^{25)}$. Condon and Ferracane highlighted that the effect of filler volume on wear resistance follows a linear relationship, with high filler volumes decreasing wear rates due to the lower expanse of resin unprotected by filler particles ${ }^{26)}$. For the fluoride releasing materials investigated in this study, no connection showed between two-body wear, hardness and filler content, which is in good agreement with some literature finding ${ }^{27)}$. Furthermore, the type, chemistry, morphology, and size of the filler have been found to influence the material hardness performance ${ }^{13,28)}$. Our study has yielded similar results as previous theoretical and experimental studies, which have declared that the restorative composite material with small-sized filler particles reveal improved hardness ${ }^{28-30)}$. SEM pictures (Fig. 4) showed that Dyract and GC Fuji II LC had relatively fine fillers and this might explained the higher Vickers hardness values. On the other hand, ACTIVA-Restorative showed significantly lower wear depth $(23 \mu \mathrm{m})$ than all other tested materials (Table 2). The finding in accordance with Bansal et al. who showed that ACTIVA-Restorative has similar wear rate as a conventional resin composite ${ }^{10)}$. This can be explained partially by the resilient resin matrix with energyabsorbing elastomeric components.

The amount of the shrinkage stress generated by the polymerization reaction of the resin containing restorative materials is the main factor for clinical problems like poor marginal adaptation, postoperative pain, and recurrent carries. The magnitude of polymerization shrinkage stress has been determined to be dependent on the extent of the reaction, the stiffness of the material and its ability to flow $^{31,32)}$. Higher filler loading of materials may result in a high degree of stiffness, which ultimately causes high shrinkage stress $^{31)}$. In this study, the polymerization shrinkage stress of the tested materials were in range between 3.4 and 3.8 MPa with no significant differences (Table 2).

When the restorative materials are exposed to or stored in water, two different mechanisms occur. First there will be uptake of water producing an increased weight (sorption) and leaching or dissolution of components from the material into the mouth (solubility) leading to reduction in weight ${ }^{33)}$. In the present study, resin modified glass ionomer after 37 days showed water uptake percentage of $5 \mathrm{wt} \%$, which was the highest among all tested materials (Fig. 2). The method of mixing may generate air voids, which may accelerate the water sorption of this material ${ }^{34)}$. Air voids incorporated in the material increases the surface exposed to moisture and may lead to inhibition zones with unpolymerized material ${ }^{34)}$. Moreover, the presence of hydrophilic constituent HEMA in GC Fuji II LC can increase its water sorption ability.

The complex process of fluoride release from restorative materials depends on several factors. Intrinsic factors such as formulation and solubility or porosity of the material affects the amount of fluoride release $^{35}$. This study evaluated the daily fluoride release from investigated materials over a period of 10 days. The results of this current study agree with others that only resin modified glass ionomer showed an initial fluoride burst effect ${ }^{35,36)}$. The first process is characterized by an initial burst of fluoride release from the surface after which the elution is markedly reduced, accompanied by the second bulk diffusion process by which small amounts of fluoride continue to be released into the surrounding media. This pattern of release has been observed in previous studies ${ }^{35,36}$. On the 1 st day the fluoride release is induced by superficial rinsing effect and during the subsequent days release is attributed to its ability to diffuse through cement pores and cracks ${ }^{37}$. The HEMA present in resin modified glass ionomer slowly absorbs water to allow for diffusion of fluoride ions $^{38)}$. In contrast to glass ionomer, compomer, giomers and bioactive resin based composite are shown to have lower fluoride release with no initial fluoride burst effect but levels of fluoride release remain relatively constant for a week. In methodology, deionized water was used as a specimen storage solution because it is easily obtainable and more fluoride is released in deionized water than in artificial saliva ${ }^{38)}$. Therefore, the amount of fluoride released cannot be expected to be released from the specimens at the same content as occurred inside ones mouth.

Despite the importance of laboratory studies to answer some questions in a short time, the real performance of restorations can only be determined by long-term clinical trials.

\section{CONCLUSION}

Within the limits of this in vitro study, it can be concluded that commercial fluoride releasing restorative materials have different properties, which should be taken into account when optimum clinical results are to be achieved. The new bioactive resin based composite (ACTIVA-Restorative), had the highest wear resistance, but an overall material performance is comparable to other compomers and giomer tested materials.

\section{ACKNOWLEDGMENTS}

Testing materials were provided by the manufacturing companies, which is greatly appreciated. This study belongs to the research activity of BioCity Turku Biomaterials Research Program (www.biomaterials.utu. fi) and it was supported by Stick Tech — member of the GC Group.

\section{CONFLICTS OF INTERESTS}

Author PV consults for Stick Tech — member of GC Group in R\&D and training. 


\section{REFERENCES}

1) McCabe JF. Resin-modified glass-ionomers. Biomaterials 1998; 19: 521-527.

2) Cattani-Lorente MA, Dupuis V, Moya F, Payan J, Meyer JM. Comparative study of the physical properties of a polyacidmodified composite resin and a resin-modified glass ionomer cement. Dent Mater 1999; 15: 21-32.

3) Yap AU, Wang X, Wu X, Chung SM. Comparative hardness and modulus of tooth-colored restoratives: a depth-sensing microindentation study. Biomaterials 2004; 25: 2179-2185.

4) van Dijken JW, Pallesen U. Fracture frequency and longevity of fractured resin composite, polyacid-modified resin composite, and resin-modified glass ionomer cement class IV restorations: an up to 14 years of follow-up. Clin Oral Investig 2010; 14: 217-222

5) Gladys S, Van Meerbeek B, Braem M, Lambrechts P, Vanherle G. Comparative physico-mechanical characterization of new hybrid restorative materials with conventional glass-ionomer and resin composite restorative materials. J Dent Res 1997; 76: 883-894.

6) Heintze SD, Ilie N, Hickel R, Reis A, Loguercio A, Rousson V. Laboratory mechanical parameters of composite resins and their relation to fractures and wear in clinical trials - A systematic review. Dent Mater 2017; 33: 101-114.

7) Kim KH, Okuno O. Micro fracture behavior of composite resins containing irregular-shaped fillers. J Oral Rehabil 2002; 29: 1153-1159.

8) van Dijken JWV. Durability of new restorative materials in class III cavities. J Adhes Dent 2011; 3: 65-70.

9) van Dijken JWV. Longevity of new hybrid restorative materials in class III cavities. Eur J Oral Sci 1999; 107: 115219.

10) Bansal R, Burgess J, Lawson NC. Wear of an enhanced resinmodified glass-ionomer restorative material. Am J Dent 2016; 29: 171-174.

11) Croll TP, Berg JH, Donly KJ. Dental repair material: a resinmodified glass-ionomer bioactive ionic resin-based composite. Compend Contin Educ Dent 2015; 36: 60-65.

12) Lassila L, Garoushi S, Vallittu PK, Säilynoja E. Mechanical properties of fiber reinforced restorative composite with two distinguished fiber length distribution. J Mech Behav Biomed Mater 2016; 60: 331-338.

13) Lien W, Vandewalle KS. Physical properties of a new siloranebased restorative system. Dent Mater 2010; 26: 337-344.

14) Rodrigues Jr SA, Scherrer SS, Ferracane JL, Della Bona A. Microstructural characterization and fracture behavior of a microhybrid and a nanofill composite. Dent Mater 2008; 24: 1281-1288.

15) Masouras K, Silikas N, Watts DC. Correlation of filler content and elastic properties of resin-composites. Dent Mater 2008; 24: 932-939.

16) Pameijer CH, Garcia-Godoy F, Morrow BR, Jefferies SR. Flexural strength and flexural fatigue properties of resinmodified glass ionomers. J Clin Dent 2015; 26: 23-27.

17) International Standardization Organization, ISO 40491992(E). Polymer-based crown and bridge material. Geneva: ISO; 1992.

18) Braem M, Finger W, Van Doren VE, Lambrechts $P$, Vanherle G. Mechanical properties and filler fraction of dental composites. Dent Mater 1989; 5: 346-348.

19) Boaro LC, Gonçalves F, Guimarães TC, Ferracane JL, Pfeifer CS, Braga RR. Sorption, solubility, shrinkage and mechanical properties of "low-shrinkage" commercial resin composites.
Dent Mater 2013; 29: 398-404.

20) Ilie N, Stawarczyk B. Evaluation of modern bioactive restoratives for bulk-fill placement. J Dent 2016; 49: 46-53.

21) Soderholm KJ, Zigan M, Ragan M, Fischlschweiger W, Bergman M. Hydrolytic degradation of dental composites. J Dent Res 1984; 63: 1248-1254.

22) Roberts T, Miyai K, Ikemura K, Fuchigami K, Kitamura T. Fluoride ion sustained release preformed glass ionomer filler and dental compositions containing the same. United States Patent No. 5, 883 (1999) 153.

23) Lazaridou D, Belli R, Petschelt A, Lohbauer U. Are resin composites suitable replacements for amalgam? A study of two-body wear. Clin Oral Investig 2015; 19: 1485-1492.

24) Manhart J, Kunzelmann KH, Chen HY, Hickel R. Mechanical properties and wear behavior of light-cured packable composite resins. Dent Mater 2000; 16: 33-40.

25) McCabe JF, Wassell RW. Hardness of model dental composites - the effect of filler volume fraction and silanation. J Mater Sci Mater Med 1999; 10: 291-294.

26) Condon JR, Ferracane J. In vitro wear of composite with varied cure, filler level, and filler treatment. J Dent Res 1997; 76: 1405-1411.

27) Hahnel S, Schultz S, Trempler C, Ach B, Handel G, Rosentritt M. Two-body wear of dental restorative materials. Mech Behav Biomed Mater 2011; 4: 237-244.

28) Ferracane JL. Correlation between hardness and degree of conversion during the setting reaction of unfilled dental restorative resins. Dent Mater 1985; 1: 11-14.

29) Kim KH, Ong JL, Okuno O. The effect of filler loading and morphology on the mechanical properties of contemporary composites. J Prosthet Dent 2002; 87: 642-649.

30) Li J, Li H, Fok AS, Watts DC. Multiple correlations of material parameters of light-cured dental composites. Dent Mater 2009; 25: 829-836.

31) Chen HY, Manhart J, Kunzelmann KH, Hickel R. Polymerization contraction stress in light-cured compomer restorative materials. Dent Mater 2003; 19: 597-602.

32) Davidson CL, Feilzer AJ. Polymerization shrinkage and polymerization shrinkage stress in polymer-based restoratives. J Dent 1997; 25: 435-440.

33) Manuel Toledano, Osorio R, Osorio E, Prati C, Garcia Godoy F. Sorption and solubility of resin based restorative dental materials. J Dent 2003; 31: 43-50.

34) Chinelatti AM, Ramos RP, Chimello DT, Palma - Dibb RG. Clinical performance of a resin modified glass-ionomer and two Poly acid modified resin composites in cervical lesions restoration: one year follow up. J Oral Rehabil 2007; 31: 251257.

35) Tiwari S, Kenchappa M, Bhayya D, Gupta S, Saxena S, Satyarth S, Singh A, Gupta M. Antibacterial activity and fluoride release of glass-ionomer cement, compomer and zirconia reinforced glass-ionomer cement. J Clin Diagn Res 2016; 10: 90-93.

36) Mousavinasab SM, Meyers I. Fluoride release by glass ionomer cements, compomer and giomer. Dent Res J (Isfahan) 2009; 6: 75-81.

37) Forsten L. Fluoride release and uptake by glass-ionomers and related materials and its clinical effect. Biomaterials 1998; 19: 503-508.

38) Bansal R, Bansal T. A Comparative evaluation of the amount of fluoride release and re-release after recharging from aesthetic restorative materials: An in vitro study. Clin Diagn Res 2015; 9: 11-14. 